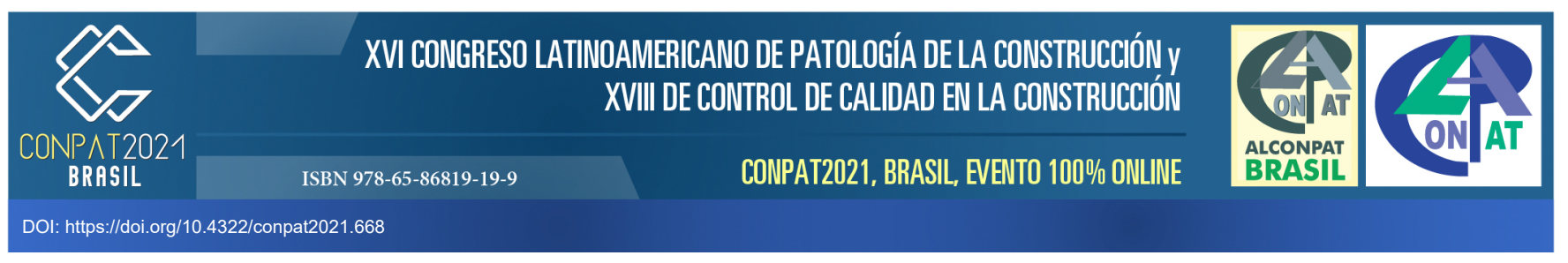

\title{
ANÁLISE DAS MANIFESTAÇÕES PATOLÓGICAS EM CAIXAS D’AGUA CONSTRUÍDAS DE CONCRETO ARMADO E AÇO NA CIDADE DE SOBRAL
}

\author{
J. R. Sabino ${ }^{1}$, G. L. A. Albuquerque ${ }^{1}$, J. C. Sales ${ }^{1 *}$ \\ *email: juscelinochaves@hotmail.com \\ ${ }^{1}$ Departamento de Engenharia Civil, Universidade Estadual Vale do Acaraú, Sobral, Brasil
}

\begin{abstract}
RESUMO
O presente trabalho teve como objetivo analisar e fazer propostas de soluções e tratamentos das manifestações patológicas existentes em duas caixas d'agua (reservatórios de água) existentes no Instituto Federal de Ciência e Tecnologia do Ceará - IFCE, no Campus da cidade de Sobral no Estado do Ceará. Como metodologia usada para realizar esse trabalho, foram feitas visitas in loco aos reservatórios (caixas d'agua), para diagnosticar as manifestações patológicas, onde também foram feitos registros fotográficos das manifestações patológicas. Dentre as manifestações patológicas que foram encontradas estão as fissuras, corrosão da armadura, destacamentos na estrutura e falhas na concretagem no reservatório 1 (Caixa d'água em concreto armado), como também corrosão na estrutura metálica do reservatório 2 (Caixa d'água em estrutura metálica). Foi possível concluir que a caixa d'água de concreto armado (Reservatório 1) construída a cerca de 10 anos atrás possui mais manifestações patológicas que a caixa d'água feita em estrutura metálica (Reservatório 2) que foi construída a cerca de 80 anos atrás.
\end{abstract}

Palavras-chave: manifestações patológicas, corrosão, reservatórios de água. 
The present work aimed to analyze proposals for solutions and treatments of pathological manifestations existing in two water tanks (water reservoirs) at the Federal Institute of Science and Technology of Ceará - IFCE, in the Campus of the city of Sobral in the state of Ceará. As a methodology used to carry out this work, on-site visits were made to the reservoirs (water tanks) to diagnose the pathological manifestations, where photographic records of the pathological manifestations were also made. Among the pathological manifestations that were found are cracks, corrosion of the reinforcement, detachments in the structure and failures in the concreting in reservoir 1 (Waterbox in reinforced concrete), as well as corrosion in the metallic structure of reservoir 2 (Waterbox in metal structure). It was possible to conclude that the reinforced concrete water tank (Reservoir 1) built about 10 years ago has more pathological manifestations than the metallic structure water tank (Reservoir 2 ) that was built about 80 years ago.

Keywords: pathological manifestations, corrosion, water reservoirs.

\section{RESUMEN}

El presente trabajo tuvo como objetivo analizar y realizar propuestas de soluciones y tratamientos de manifestaciones patológicas existentes en dos tanques de agua (reservorios de agua) en el Instituto Federal de Ciencia y Tecnología de Ceará - IFCE, en el Campus de la ciudad de Sobral en el estado de Ceará. Como metodología utilizada para realizar este trabajo, se realizaron visitas in situ a los reservorios (tanques de agua) para diagnosticar las manifestaciones patológicas, donde también se realizaron registros fotográficos de las manifestaciones patológicas. Dentre as manifestações patológicas que foram encontradas estão as fissuras, corrosão da armadura, destacamentos na estrutura e falhas na concretagem no reservatório 1 (Caixa d'água em concreto armado), como também corrosão na estrutura metálica do reservatório 2 (Caixa d'água em estructura metálica). Se pudo concluir que el tanque de agua de hormigón armado (Embalse 1) construido hace unos 10 años tiene más manifestaciones patológicas que el tanque de agua de estructura metálica (Embalse 2) que se construyó hace unos 80 años.

Palabras-clave: manifestaciones patológicas, corrosión, reservorios de agua. 


\section{INTRODUÇÃO}

A patologia das estruturas é um campo da engenharia das estruturas que tem como principal objetivo o estudo das origens, formas de manifestação, consequências e mecanismos de ocorrência das falhas e dos sistemas de degradação das estruturas. A patologia, além de ser um campo de estudos e atuação que identifica anomalias, também se refere à concepção e ao projeto das estruturas (Souza e Ripper, 1998).

A investigação patológica de um edifício para posterior formulação de um plano de ações interventivas envolve uma série de decisões técnicas e não lineares, havendo necessidade de entendimento dos fenômenos como um todo para que a decisão tomada seja a mais adequada conforme o quadro de patologias apresentado (Zuchetti, 2015).

Os reservatórios hidráulicos são estruturas destinadas a armazenar água para depois distribuir a água para as casas, prédios e outros tipos de construções. Por ter como função principal, o armazenamento de água, estes reservatórios devem ter atenção redobrada, pois a água é um dos principais agentes causadores das mais diversas patologias, tais como: infiltrações, mofos/bolores, eflorescências, manchas úmidas, entre outros. Dessa forma, suas estruturas devem ser estanques, impedindo que a água saia ou penetre dentro da estrutura.

Pesquisadores fizeram uma redistribuição de esforços em um reservatório de água devido à recalques nas fundações (Souza, 2021). O recalque nas fundações gera manifestações patológicas nas estruturas como os reservatórios de água.

Esse estudo foi desenvolvido com dois reservatórios no Campus do IFCE - Instituto Federal de Educação, Ciência e Tecnologia do Ceará-IFCE, Campus Sobral, e localizam-se próximo a Biblioteca do IFCE e próximo ao Bloco do Recursos Hídricos do IFCE. Desta forma, o estudo engloba todos os reservatórios hidráulicos elevados do campus.

Sendo assim, o problema das manifestações patologias nos reservatórios é algo importante e que merece ser estudado, pois caso estas patologias não sejam tratadas, podem evoluir para uma forma mais grave, que pode até mesmo gerar o colapso da estrutura. No Campus do IFCE existem dois reservatórios de água que apresentam muitas patologias, então, com a realização deste trabalho pretende-se mostrar o panorama geral das patologias nestas estruturas e ao final propor soluções de tratamentos.

Existem várias manifestações patológicas encontradas nos reservatórios hidráulicos, que vão desde simples manchamento até mesmo grandes rachaduras em pilares, comprometendo a segurança das estruturas.

O tema desse trabalho é a identificação e proposta de soluções de tratamentos para as patologias em reservatórios de água elevados, para poder realizá-lo de forma satisfatória, faz necessário que seja delimitado o campo de pesquisa. Para tanto, este estudo foi desenvolvido com dois reservatórios no Campus do IFCE - Instituto Federal de Educação, Ciência e Tecnologia do CearáIFCE-Campus Sobral.

O primeiro objetivo desse trabalho foi realizar a inspeção visual através de visitas in loco nos reservatórios de água elevados existentes no Campus do IFCE em Sobral, e identificar as manifestações patológicas em dois reservatórios de água com registro fotográfico e o segundo objetivo foi discutir as causas dessas manifestações patológicas.

\section{METODOLOGIA}

Como metodologia usada para realizar esse trabalho foram feitas visitas in loco as caixas d'agua (dois reservatórios de água) do Campus Instituto Federal de Educação, Ciência e Tecnologia do Ceará-IFCE na cidade de Sobral localizada no Estado do Ceará, para diagnosticar as manifestações 
patológicas, onde também foram feitos registros fotográficos das manifestações patológicas na hora da inspeção visual.

Foi feita também uma pesquisa de cunho bibliográfico de algumas das principais manifestações patológicas que ocorrem em reservatórios de água.

No final do trabalho foram feitas propostas para solucionar as manifestações patológicas encontradas nos reservatórios de água elevados (caixas d'agua).

\section{REVISÃO BIBLIOGRÁFICA}

A engenharia usa o termo patologia para estudar nas construções as manifestações, suas origens, seus mecanismos de ocorrência das falhas e seus defeitos que alteram o aspecto estrutural e visual de uma edificação (Nazario, 2011).

O estudo da patologia na engenharia civil é de suma importância, uma vez que é a garantia de não haver problemas futuros, adquirindo a melhoria da habitabilidade e na durabilidade do empreendimento construído, demostrando as possíveis intervenções, a fim de solucionar os eventuais problemas patológicos (Andrade, 2020).

As patologias nas construções podem se originar em uma das três fases (ou combinação delas): projeto, execução e manutenção. Sem o planejamento adequado muitas decisões acabam sendo tomadas durante a obra ou são completamente ignoradas, prejudicando a qualidade da edificação (Carvalho, 2020).

O principal e mais frequente mecanismo químico de deterioração das estruturas de aço é a corrosão metálica. A corrosão é definida como um processo espontâneo, provocada pela interação química do metal com o ambiente (Bolina, 2019).

O processo produtivo de um empreendimento, na construção civil, iniciasse pela concepção do projeto. E nessa etapa que são estabelecidos os aportes necessários para o desenvolvimento do empreendimento. As falhas no projeto são apontadas como as principais causas dos problemas patológicos na Construção Civil (Oliveira, 2013).

\subsection{Principais manifestações patológicas em reservatórios de água}

As principais manifestações patológicas em reservatórios de água são: corrosão nas armaduras, fissuras, destacamento, vazamentos, corrosão na estrutura metálica, mofo e eflorescências.

\subsubsection{Fissuras}

Segundo Gonçalves (2015), em todas as construções, que tem sua estrutura executada em concreto, fissuras podem surgir depois de anos, dias ou mesmo horas. A Figura 01 mostra um exemplo de fissuras nas vigas em reservatórios de concreto armado. 

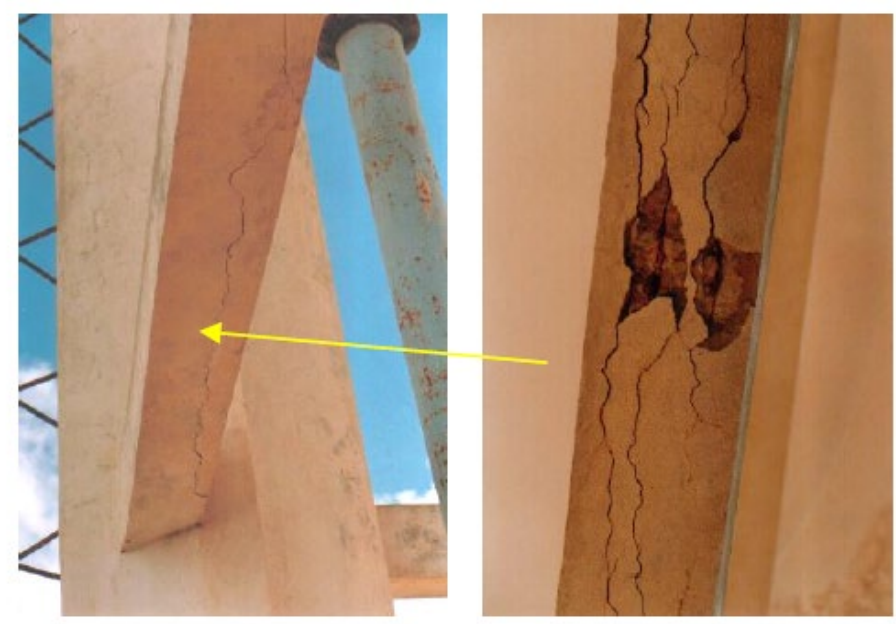

Figura 01. Fissuras na viga de reservatório de concreto armado. Fonte: Borges (2008).

\subsubsection{Falhas no projeto}

Falhas no projeto final de engenharia podem levar a escolha de elementos de projeto inadequados e gerar problemas, afetando a qualidade, o desempenho e até mesmo a vida útil do elemento. A falta de critério e uma má definição das ações atuantes na edificação, como por exemplo, escolha inadequada do modelo analítico, deficiência de cálculo da estrutura ou da avaliação da capacidade portante do solo, incompatibilidade do projeto arquitetônico com os demais (estrutural, hidráulico, elétrico etc.), especificação do cobrimento incorreto de acordo com agressividade do ambiente dentre outros. Todas estas implicações discorrem durante a fase de concepção do projeto, daí a importância desta fase do processo relacionada com o não surgimento de patologias (Pina, 2013). Se ocorrer erro no projeto isso irá acarretar manifestações patológicas nos reservatórios que armazenam água

\subsubsection{Corrosão nas armaduras}

Para Souza e Ripper (1998), no caso das barras de aço imersas no concreto, a deterioração é caracterizada pela destruição da película passivante existente ao redor de toda a superfície exterior das barras. Esta película é formada como resultado do impedimento da dissolução do ferro pela elevada alcalinidade da solução aquosa que existe no concreto. A corrosão das armaduras é um processo eletroquímico que para ocorrer necessita da presença simultânea de umidade, oxigênio e ddp (diferença de potencial). A Figura 02 mostra a corrosão em pilar de reservatório de concreto armado. 


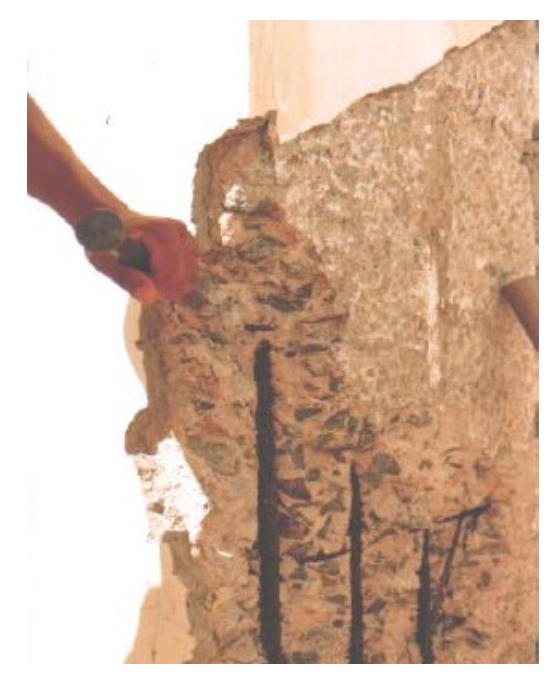

Figura 02. Corrosão em pilar de reservatório de concreto armado. Fonte: Borges (2008).

Na Figura 03, é mostrado um exemplo de destacamento do concreto que envolve a armadura em uma viga de um de reservatório de água. Também é possível perceber a existência de fissuras no pilar do reservatório.

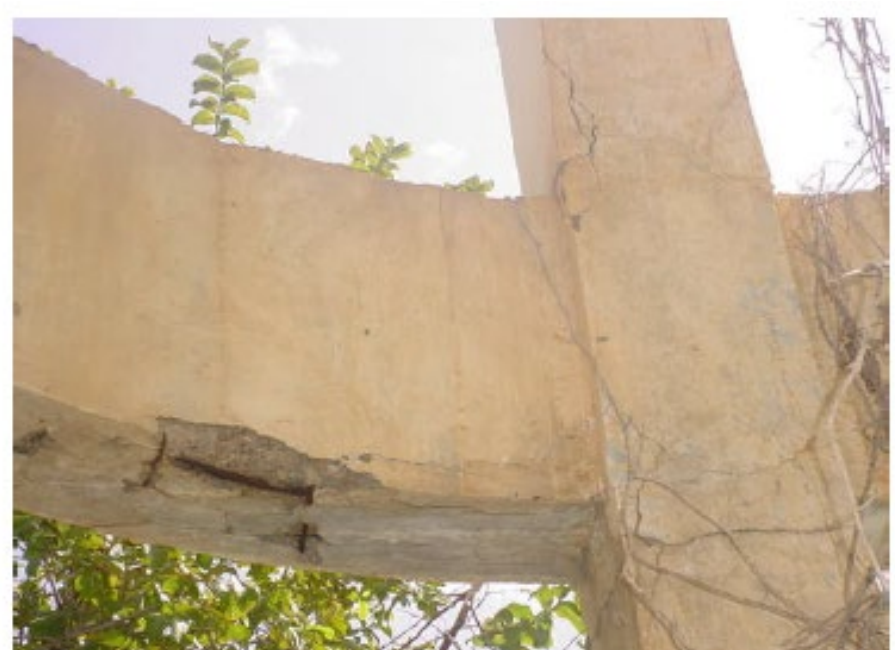

Figura 03. Destacamento em reservatório de concreto armado. Fonte: Borges (2008).

\subsubsection{Mofo}

O mofo é uma manifestação patológica muito encontrada nos reservatórios de água elevados (caixas d'agua) construídos em concreto armado. A Figura 04 mostra a manifestação patológica do mofo em uma estrutura de um reservatório de água construído em concreto armado na cidade de Sobral no Estado do Ceará. 


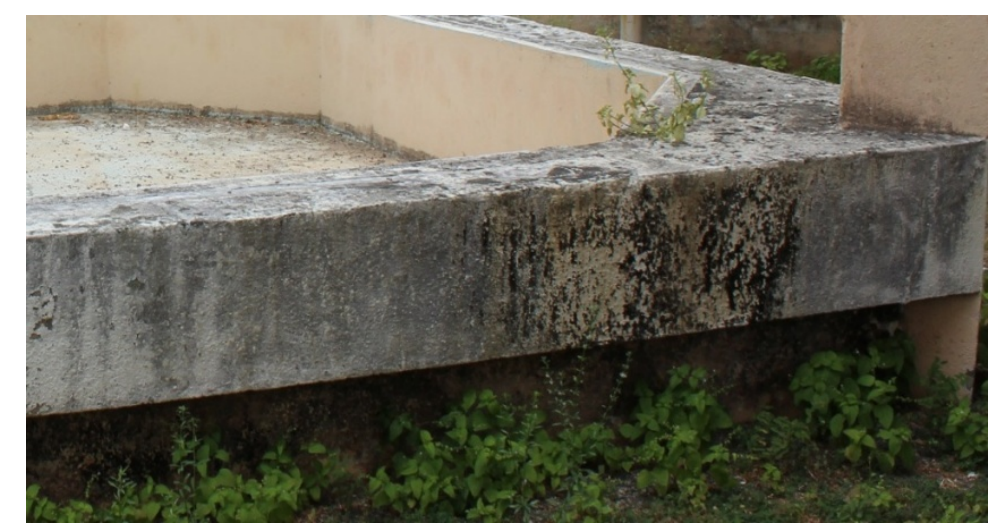

Figura 04. Mofo em um reservatório de concreto armado. Fonte: Autor (2017).

\section{MANIFESTAÇÕES PATOLÓGICAS NAS CAIXAS D’AGUA FEITAS DE CONCRETO E DE AÇO NO CAMPUS DO IFCE EM SOBRAL}

A seguir são apresentadas e discutidas as manifestações patológicas encontradas para cada um dos dois reservatórios inspecionados nessa pesquisas. Para o Reservatório 1- Caixa d'água em concreto armado do IFCE, as manifestações patológicas identificadas foram: fissuras, destacamentos, falhas na concretagem e corrosão de armaduras, enquanto que no Reservatório 2-Caixa d'água metálica IFCE, encontrou-se apenas corrosão.

\subsection{Reservatórios no Campus do IFCE}

No Campus do IFCE (Instituto Federal de Educação, Ciência e Tecnologia do Ceará) existem dois reservatórios elevados em que suas estruturas foram construídas de dois tipos de materiais diferentes, onde um é em concreto armado (Reservatório 1) e o outro é feito de aço (Reservatório 2).

\subsubsection{Reservatório 1- Caixa d'água em concreto armado IFCE}

Na Figura 05 é mostrado uma vista do Castelo d'água, o Reservatório 1-Caixa d'água IFCE, a segunda estrutura inspecionada, constituída por elementos pré-moldados de concreto armado. 


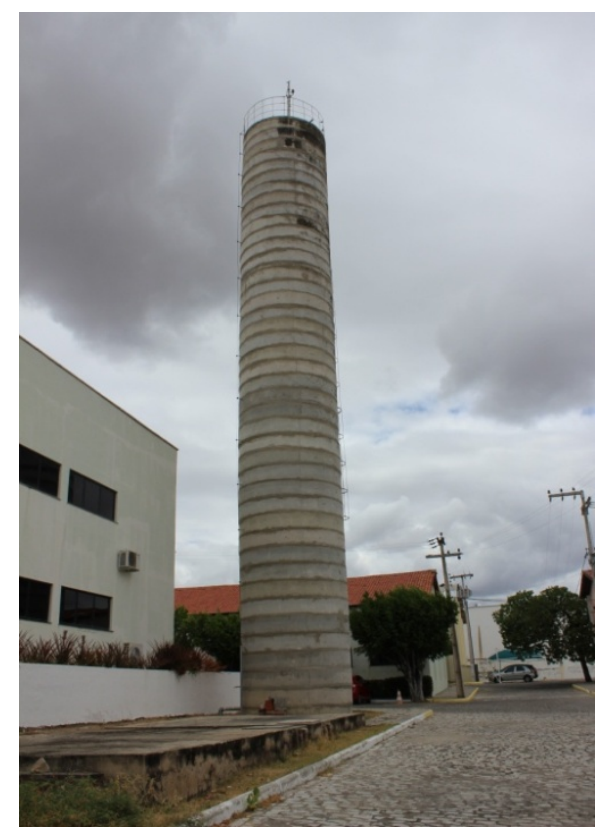

Figura 05. Reservatório 1- Caixa d'água IFCE. Fonte: Autor (2017).

Na Figura 06, verifica-se a presença de fissuras podem ter sido ocasionadas pela variação de temperatura, sendo chamadas neste caso de fissuras por retração. Também pode ter ocorrido por esforço de tração, aliado a falta de recobrimento mínimo da armadura.

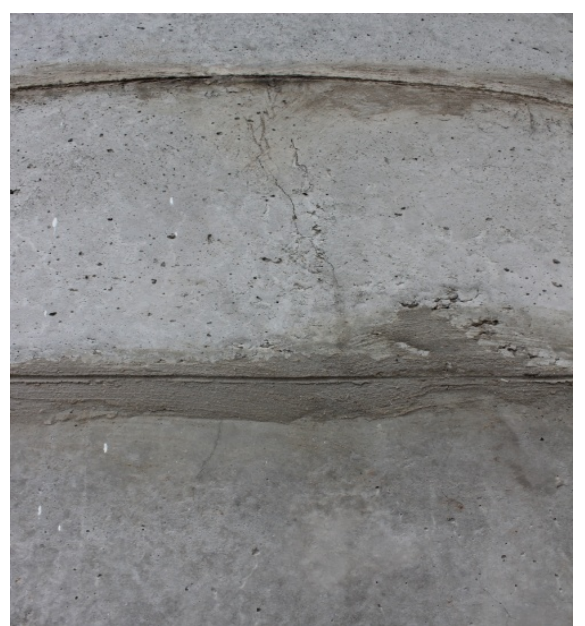

(A)

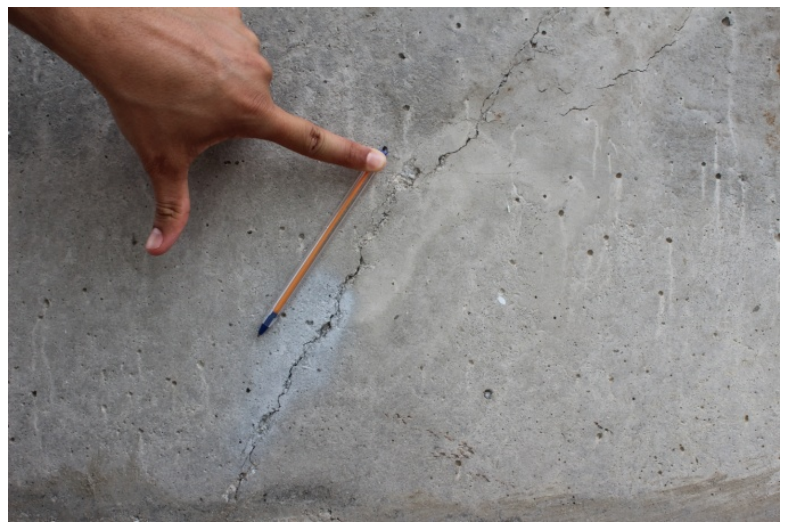

(B)

Figura 06. Fissuras na estrutura do Reservatório 1. Fonte: Autor (2017).

Na Figura 07, observa-se que existem destacamentos do cobrimento da armadura. Essa manifestação patológica pode ser ocasionada por movimentação da estrutura de concreto, deficiência do material, pelo cobrimento insuficiente da armadura ou pela ação de intempéries e agentes agressivos externos. 


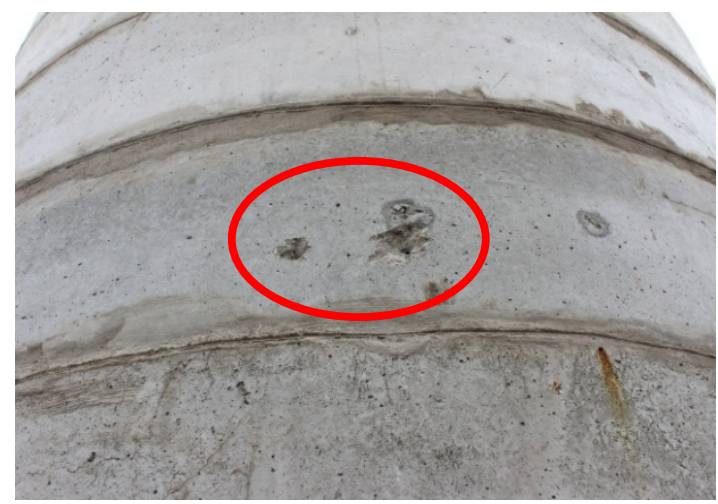

(A)

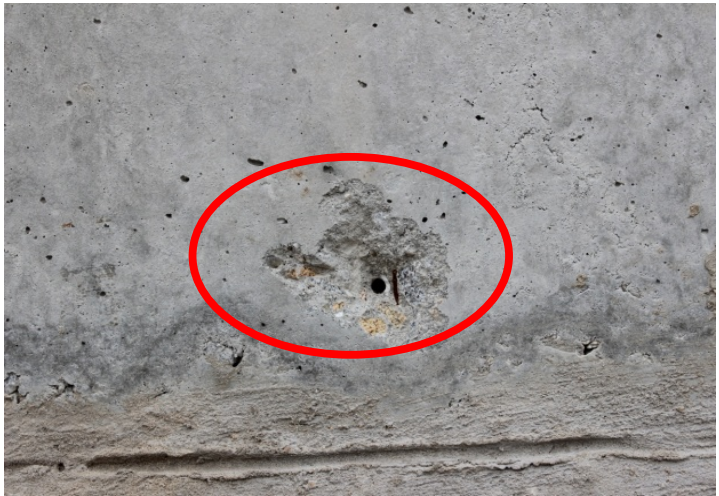

(B)

Figura 07. Destacamentos na estrutura do Reservatório 1. Fonte: Autor (2017).

A Figura 08, mostra as falhas na concretagem (bicheiras), que foram ocasionadas durante a execução por uso de formas inadequadas e de materiais de baixa qualidade.

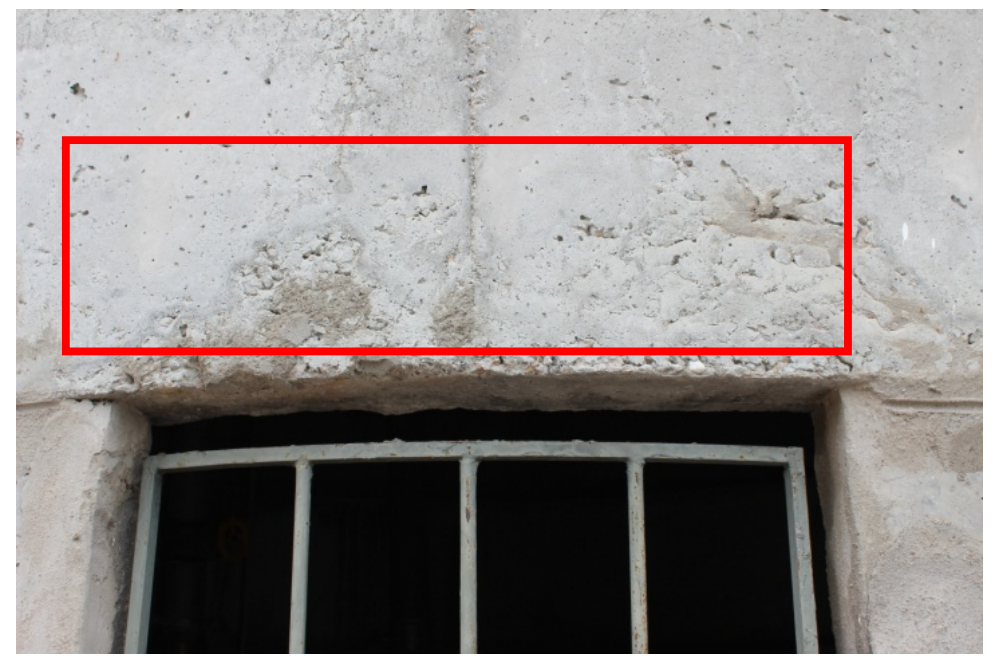

Figura 08. Falhas na concretagem na estrutura do Reservatório 1. Fonte: Autor (2017).

A Figura 09 apresenta a corrosão de armaduras, esta patologia se apresenta no local onde houve destacamento do cobrimento do concreto. A armadura ficou exposta aos agentes agressivos, perdendo assim sua camada passivadora sofrendo corrosão. 


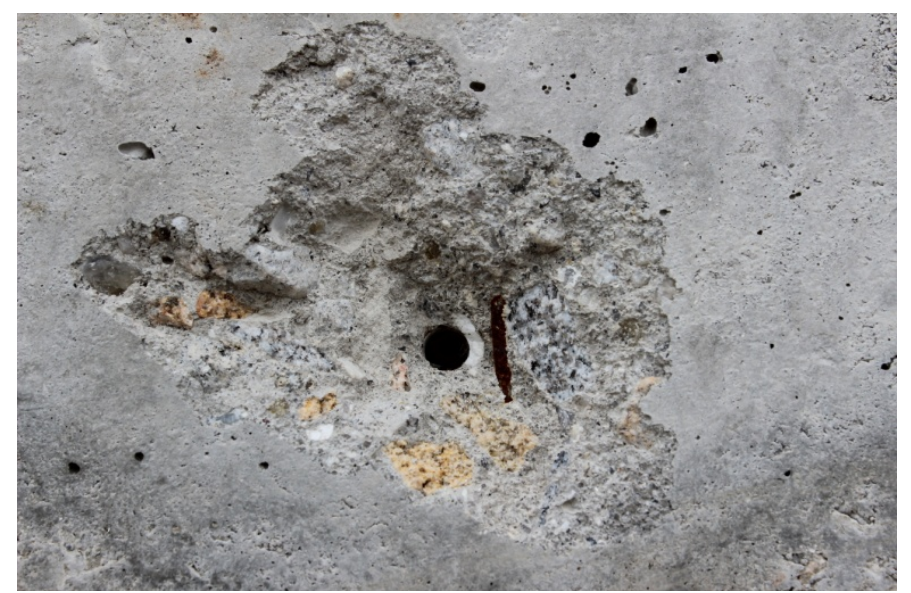

Figura 09. Início de corrosão na estrutura do Reservatório 1. Fonte: Autor (2017).

\subsubsection{Reservatório 2- Caixa d'água metálica IFCE.}

Na Figura 10 é mostrado uma vista do Reservatório 2-Caixa d'água metálica IFCE, a última estrutura inspecionada, no qual é toda metálica.

O reservatório de água 2 foi construído em estrutura metálica diferente no reservatório 1 construído em estrutura de concreto armado.

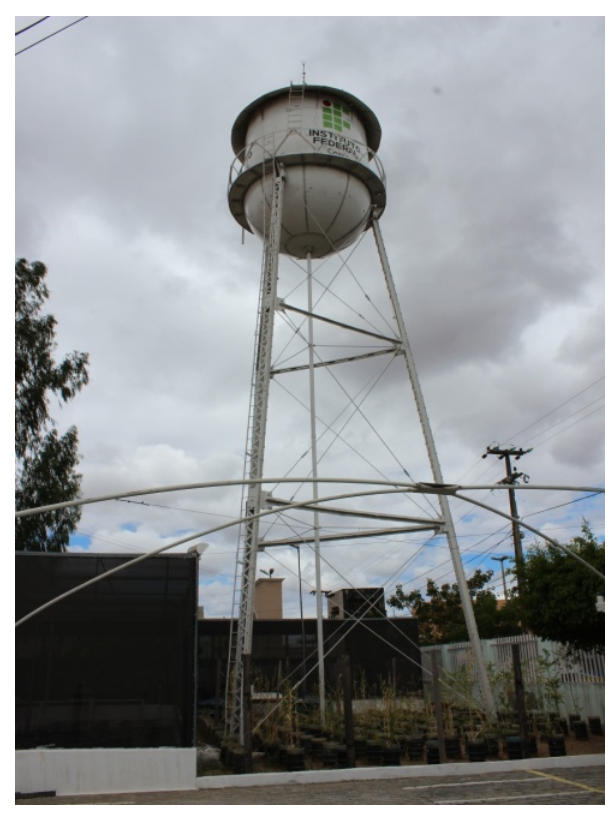

Figura 10. Reservatório 2-Caixa d'água metálica IFCE. Fonte: Autor (2017).

Para o Reservatório 2-Caixa d'água metálica IFCE, a única manifestação patológica constatada foi apenas corrosão em alguns pontos localizados da estrutura. Na Figura 11 observa-se a corrosão da parte superior do reservatório, indicado pelo círculo vermelho. 


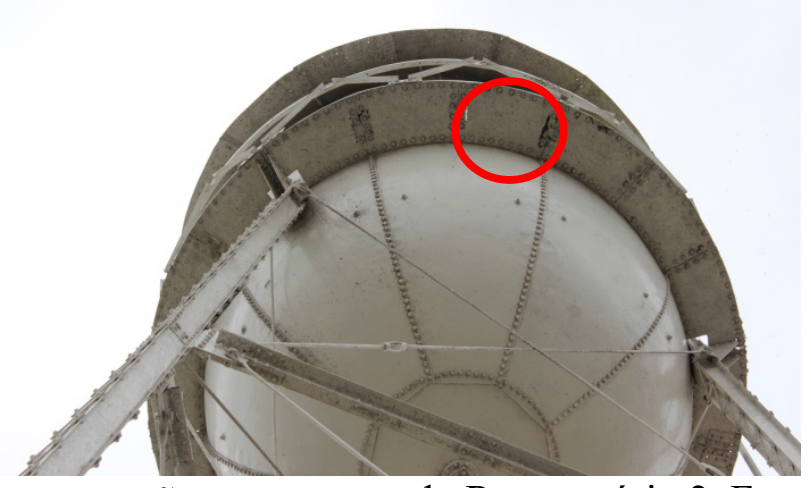

Figura 11. Ponto com corrosão na estrutura do Reservatório 2. Fonte: Autor (2017).

Na Figura 12 observa-se outro ponto de corrosão, neste caso na viga horizontal. Observa-se que uma parte da estrutura já foi corroída e que a corrosão avança ao longo da viga metálica.

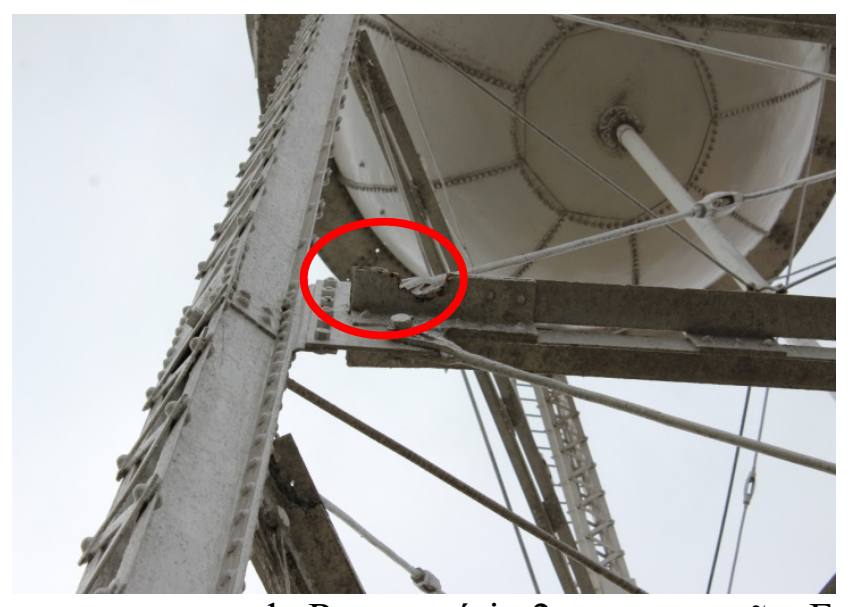

Figura 12. Outro ponto na estrutura do Reservatório 2 com corrosão. Fonte: Autor (2017).

Por fim, na Figura 13, tem-se a corrosão interna em uma viga horizontal, na qual verifica-se que a corrosão já está passando para o outro elemento que está ligado à viga.

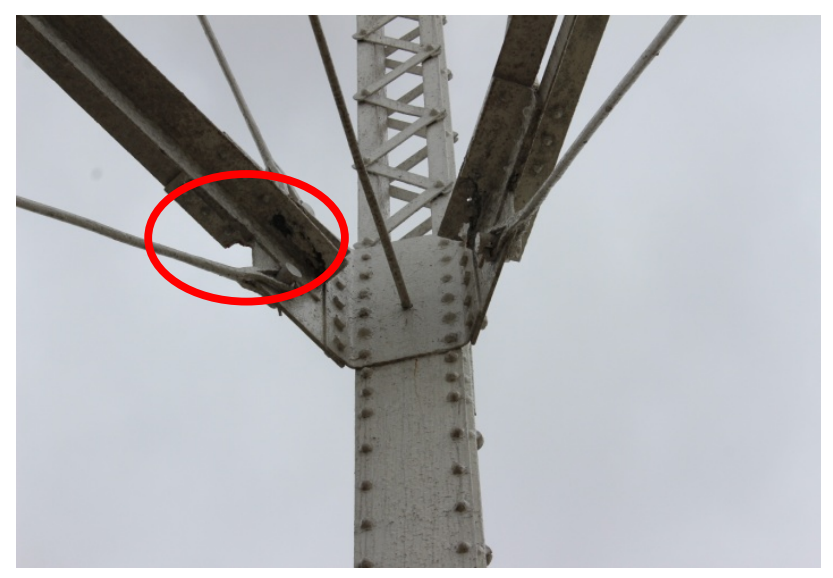

Figura 13. Corrosão na estrutura do Reservatório 2. Fonte: Autor (2017). 
Para todos os pontos com corrosão do Reservatório 2, pode-se inferir que a causa dessa patologia está ligada a ausência ou falha na pintura impermeabilizante.

\subsection{Propostas de soluções e tratamentos das manifestações patológicas}

As propostas de soluções e tratamentos das manifestações patológicas para os dois reservatórios são de grande importância para o aumento da vida útil de ambos os reservatórios.

\subsubsection{Reservatório 1-Castelo d'água em concreto armado IFCE}

Para o Reservatório 1-Castelo d'água em concreto armado IFCE, as propostas para tratar as patologias encontradas são apresentadas a seguir.

Para a recuperação da estrutura causada pelas fissuras, deve-se incialmente identificar o comportamento deste tipo de patologia, saber se a fissura se encontra em movimento com o passar do tempo, ou está estabilizada, ou seja, sem movimentação. A partir dessa análise pode-se indicar um tratamento com material elástico ou não, de acordo com a necessidade de cada físsura.

No caso específico do Reservatório 1-Caixa d'água IFCE, deve-se associar a terapia das fissuras à uma impermeabilização, tendo em vista a posição das fissuras pode vir a trazer vazamentos. Indicase o uso de poliuretano hidroexpansivo em gel e a resina acrílica aquosa para impermeabilização, por injeção, de qualquer trinca que venha possibilitar vazamentos. Todos os locais onde haja a possibilidade de surgência de água através de trincas, fissuras, ninhos de concretagem, juntas frias e juntas de concretagem devem ser impermeabilizados.

Para tratar o problema dos destacamentos neste reservatório, observou-se que pela simplicidade da patologia e por estar no início, será realizado uma simples correção com limpeza da superfície seguido de raspagem e preenchimento do local do destacamento com uma pintura apropriada para tratar tal patologia.

Para recuperação da estrutura devido, as falhas na concretagem, deve-se preencher as falhas ocasionadas pela má vibração do concreto durante a concretagem com a utilização de graute ou adesivo epóxi.

Já nos casos de corrosão de armaduras, vale salientar que, assim como no reservatório as corrosões também estão em fase inicial e não houve perda de seção. Aqui deve-se fazer a escarificação e demolição do concreto no entorno na armadura corroída, posteriormente faz-se a limpeza da armadura, retirando-se a crosta de corrosão com lixa e escova metálica. Com a armadura limpa deve-se aplicar um prime inibidor adequado para proteger de nova corrosão. Por último recompõem-se o concreto com a aplicação de microconcreto com desforma respeitando o tempo de cura.

\subsubsection{Reservatório 2- Caixa d'água metálica IFCE}

No Reservatório 2-Caixa d'água metálica IFCE, foram observados alguns pontos de corrosão pela estrutura metálica. Para o tratamento deste tipo de manifetaçaõ patológica, primeiro devemos analisar o grau de deterioração da peça. Se a corrosão estiver em estágio inicial, pode-se recorrer à limpeza superficial, secagem do interior da fenda e vedação com um líquido selante.

No caso de corrosões que geram corrosões por pites perfurações em peças sem uma perda notável de massa e peso da estrutura, a intervenção deve ser realizada com base no estado em que o processo corrosivo se encontra. Deve-se efetuar a limpeza no local e se a estrutura não estiver comprometida, pode-se cobrir o furo aplicando sobre ele um selante especial. É importante a experiência do fiscal devido a possibilidade de se necessitar de uma intervenção mais complexa, com reforço da estrutura ou até mesmo substituição de peças. 
Para o Reservatório 1- Caixa d'água em concreto armado IFCE, este foi o mais crítico apresentando as manifestações patológicas: falhas na concretagem, destacamentos na estrutura, fissuras, corrosão da armadura. As manifestações patologias mais críticas neste reservatório, foram as fissuras.

Por fim, o reservatório em estado menos crítico foi o Reservatório 2- Caixa d'água metálica IFCE, o qual apresentou apenas a corrosão da estrutura metálica como manifestação patológica.

\section{CONCLUSÃO}

Esse trabalho objetivou identificar as manifestações patológicas em reservatórios de água do Campus do Instituto Federal do Ceará- IFCE em Sobral-CE e propor soluções de tratamento.

Os reservatórios hidráulicos são estruturas de grande importância que tem o objetivo de armazenar água para consumo humano. As manifestações patológicas presente nos reservatórios podem comprometer seriamente a sua estabilidade e a segurança estrutural. Existem vários erros que levam ao aparecimento de patologias, esses erros podem acontecer durante a fase do projeto, já durante a execução ou até mesmo pela falta de manutenção e uso inadequado da estrutura.

Com a identificação das manifestações patológicas encontradas nos reservatórios estudados, foi possível concluir que o reservatório que apresentou o maior número de patologias e, consequentemente, o estado mais crítico foi o Reservatório 1- Castelo d'água em concreto armado IFCE. Além disso, dentre as patologias encontradas, a patologia que se encontrava em estado mais crítico de deterioração da estrutura foram as trincas.

A caixa d'água de concreto armado construída a cerca de 10 anos atrás apresentou mais manifestações patológicas que a caixa d'água feita em estrutura metálica (Reservatório 2) que foi construída a cerca de 80 anos atrás. A manutenção bem-feita ao longo dos anos na caixa d'agua feita de aço, proporcionou a existência menos manifestações patológicas que a caixa d'agua de concreto armado. Os dois reservatórios estão cerca de $60 \mathrm{~m}$ de distância um do outro.

Os reservatórios de água elevados do Campus do Instituto Federal do Ceará em Sobral-CE, apresentam muitas patologias, estas que se não forem tratadas podem evoluir ainda mais e comprometer seriamente a estrutura. Com isso, a realização deste estudo pode ser justificada pela necessidade de se identificar as origens, as causas e os mecanismos de ocorrências destas patologias.

É importante propor soluções de tratamentos adequadas utilizando procedimentos adequados de recuperação ou proteção da estrutura deteriorada, com o intuito de prolongar a vida útil destes reservatórios, além de garantir a segurança e estabilidade destes.

\section{REFERÊNCIAS}

Bolina, F. C.; Tutikian, B. F.; Helene, P. R. L. (2019). "Patologia das Estruturas". Editora Oficina de Textos, São Paulo.

Borges, M. C. (2008). “Manifestações patológicas incidentes em reservatórios de água elevados executados em concreto armado". Monografia (Graduação em Engenharia Civil), Universidade Estadual de Feira de Santana, Feira de Santana.

Carvalho, M. (2020). "Patologias na Construção Civil - Tipos e Causas". Disponível em: $<$ https://carluc.com.br/manutencao-predial/patologias-na-construcao-civil/>. Acesso em: 07 mai. 2021. 
Gonçalves, E. A. B. (2015). "Estudo de patologias e suas causas nas estruturas de concreto armado de obras de edificações". Monografia (Graduação em Engenharia Civil), Universidade Federal do Rio de Janeiro, Rio de Janeiro.

Nazario, D.; Zacan, E. C. (2011). “Manifestações das patologias construtivas nas edificações públicas da rede municipal de Criciúma: Inspeção dos sete postos de saúde”. UNESC Universidade do Extremo Sul Catarinense.

Oliveira, D.F. (2013). "Levantamento de causas de patologias na construção civil" [S.1]: Universidade Federal do Rio de Janeiro.

Pina, G.L. (2013). "Patologia nas habitações populares". Monografia (Graduação em Engenharia Civil), Universidade Federal do Rio de Janeiro, Rio de Janeiro.

Souza, A.; Monteiro, E.; Batista, T. (2017). "Manifestações patológicas encontradas em reservatórios de água de edifício residencial". In: Conferência Nacional de Patologia e Recuperação de Estruturas. Anais...Recife.

Souza, V.C.M.; Ripper, T. "Patologia, recuperação e reforço de estruturas de concreto". [S.1]: Pini, 1998.

Souza, V. T. C. et al. (2021). "Redistribuição de esforços em um reservatório de água devido à recalques nas fundações". In: XVII Congreso International sobre Patologiay and Rehabilitation de la Construcciones- CINPAR. Anais... Online.

Zuchetti, P. A. B. (2015). "Patologias da construção civil: investigação patológica em edificio corporativo de administração pública no Vale do Taquari/RS". 2015. Monografia (Graduação em Engenharia Civil) - Universidade do Vale do Taquari - UNIVATES, Lajeado. Disponível em: $<$ http://hdl.handle.net/10737/939>. Acesso em: 27 mai. 2021. 